\title{
Commentary: Father Time versus Mother Nature: Outcomes in stage I esophageal adenocarcinoma
}

Jules Lin, MD

\author{
From the Section of Thoracic Surgery, Department of Surgery, University of Michigan Medical Center, Ann Ar- \\ bor, Mich. \\ Disclosures: Author has nothing to disclose with regard to commercial support. \\ Received for publication Oct 8, 2019; revisions received Oct 8, 2019; accepted for publication Oct 8, 2019; \\ available ahead of print Nov 14, 2019. \\ Address for reprints: Jules Lin, MD, Section of Thoracic Surgery, 1500 E. Medical Center Dr, 2120TC/5344, Ann \\ Arbor, MI 48109-5344 (E-mail: juleslin@umich.edu). \\ J Thorac Cardiovasc Surg 2020;159:1638-9 \\ $0022-5223 / \$ 36.00$ \\ Copyright $(2019$ by The American Association for Thoracic Surgery \\ https://doi.org/10.1016/j.jtcvs.2019.10.046
}

In this issue of the Journal, Raman and colleagues ${ }^{1}$ report that undergoing esophagectomy more than 100 days after diagnosis was associated with decreased survival and increased positive margins in patients with stage I esophageal adenocarcinoma in the National Cancer Database (NCDB). Timely care is 1 of 6 domains of quality health identified in the Institute of Medicine report "Crossing the Quality Chasm."2 Although there are some limitations inherent to the NCDB, the results are of interest with the risk of increasing treatment times due to growing patient volume and capacity constraints as well as efforts to increase regionalization of care.

Treatment for superficial cancers has markedly changed during the 11-year study period, and the majority of T1a esophageal adenocarcinomas are now treated by endoscopic mucosal resection (EMR). The study results may not apply to current practice since the study group included both T1a and T1b tumors. However, the NCDB started distinguishing T1a and T1b esophageal cancers in 2011, and in a limited analysis of a small number of patients, the authors found that time to surgery greater than 100 days was associated with worse survival for both T1a and T1b patients. EMR has also become a staging tool in distinguishing T1a from T1b tumors. Although patients undergoing EMR alone were excluded from the study, those undergoing EMR followed by surgery due to positive margins or tumor depth were included, although it is unclear whether the increase in time from diagnosis to surgery due to EMR had any effect on survival, since the NCDB only tracks the most definitive procedure. A study by Plum and colleagues ${ }^{3}$ found that disease-free survival was inferior in patients who underwent EMR followed by surgery compared with a primary surgery group.

Although efforts at increasing regionalization of care especially for complex procedures like esophagectomy have shown better outcomes at centralized hospital systems ${ }^{4}$ it is important to determine the balance between

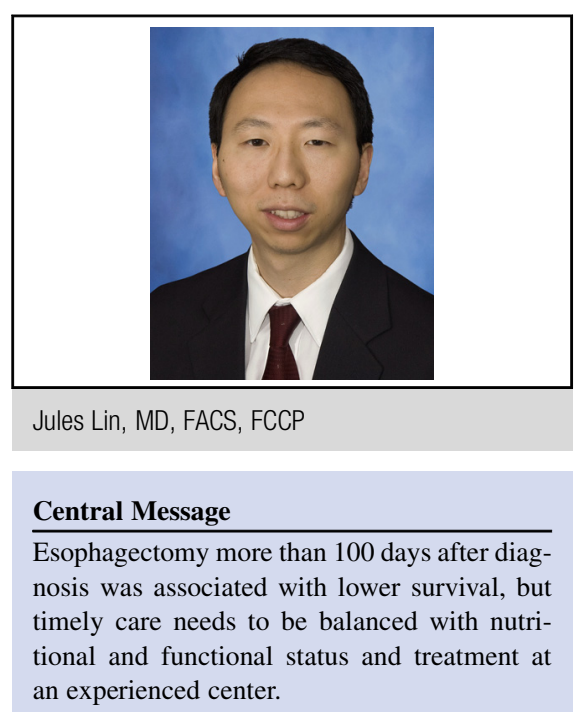

See Article page 1626. improved outcomes associated with center and surgeon experience and time to surgery greater than 100 days due to traveling further distances and increasing capacity constraints. Bilimoria and colleagues ${ }^{5}$ found that patients diagnosed and treated at different hospitals were significantly more likely to have wait times $>30$ days for 8 different cancers using the NCDB. Raman and colleagues found that even though high-volume hospitals were associated with a time to surgery beyond 100 days, treatment at a highvolume center was relatively more important and was still associated with improved survival, suggesting that patients should continue to receive care at high-volume centers but that efforts should be made to decrease the time to surgery when possible.

Although the authors found a significant association between time greater than 100 days from diagnosis to esophagectomy in stage I esophageal adenocarcinomas and a small decrease in survival, one must balance the need for adequate staging, optimizing the patient's nutritional and functional status, and treatment at an experienced center in the fight between Father Time and Mother Nature.

\section{References}

1. Raman V, Jawitz O, Voigt S, Chi-Fu Y, Wang H, Harpole D, et al. Effect of time to surgery on outcomes in stage I esophageal adenocarcinoma. J Thorac Cardiovasc Surg. 2020;159:1626-35.e1.

2. Institute of Medicine (US) Committee on Quality of Health Care in America. Crossing the Quality Chasm: A New Health System for the 21st Century. Washington, DC: National Academies Press; 2001. 
3. Plum PS, Hölscher AH, Pacheco Godoy K, Schmidt H, Berlth F, Chon SH, et al. Prognosis of patients with superficial T1 esophageal cancer who underwent endoscopic resection before esophagectomy-a propensity score-matched comparison. Surg Endosc. 2018; $32: 3972-80$
4. Sheetz KH, Dimick JB, Nathan H. Centralization of high-risk cancer surgery within existing hospital systems. J Clin Oncol. 2019;JCO1802035.

5. Bilimoria KY, Ko CY, Tomlinson JS, Stewart AK, Talamonti MS, Hynes DL, et al Wait times for cancer surgery in the United States: trends and predictors of delays. Ann Surg. 2011;253:779-85. 